\title{
Effect of advanced simulation training with digital feedback on dental faculty's competency in tooth preparation: A pre-post design
}

\section{Xiaoxiang $\mathrm{Xu}$}

Peking University School of Stomatology

Qiufei Xie

Peking University School of Stomatology

Yongsheng Zhou

Peking University School of Stomatology

Lei Wu

Nissin dental products

Ye Cao ( $\nabla$ ye.cao@bjmu.edu.cn )

Peking University School of Stomatology

Research article

Keywords: Dental education, digital evaluation system, faculty development, prosthodontics, tooth preparation

Posted Date: August 31st, 2019

DOl: https://doi.org/10.21203/rs.2.13731/v1

License: (c) (i) This work is licensed under a Creative Commons Attribution 4.0 International License. Read Full License 


\section{Abstract}

Background $\mathbb{Z}$ Crown preparation is one of the most essential techniques in dentistry and represents a very important topic in preclinical dental education. It is obligatory for prosthodontic faculty to master this technique and demonstrate it during live operation for preclinical simulation training. Standardized tooth preparation training in simulated environment should be provided for preclinical instructors to improve their teaching performance. This study aimed to investigate the effect of advanced simulation training with digital feedback on dental faculty's competency in tooth preparation. Methods $\varangle$ Fifty prosthodontic faculty from 49 dental schools in China participated in this training program. Prior to the training course, all trainees were required to prepare the maxillary right central incisor (11\#) for a ceramo-metal crown and the mandibular left first molar (36\#) for a metal crown with the standard typodont tooth. Training started with the same preparations using on-site simulation facilities with 30 minutes provided for each preparation. These were graded by a digital evaluation system and adopted as pre-training competency. Then, a didactic instruction and a live demonstration about standardized tooth preparation was delivered by a senior fixed prosthodontic specialist. This was followed by three rounds of practice. All the preparations were digitally evaluated and feedback was provided to the corresponding operators. Finally, a summative examination was conducted, and the final preparations were digitally graded as posttraining competency. Results $\$ Total scores of $11 \#$ and $36 \#$ preparations in the final test were significantly increased compared to the pre-training scores. Marks deducted for amount of reduction and margin line of prepared $11 \#$ and $36 \#$, and taper of prepared $36 \#$, were significantly decreased compared to that before training. Conclusions $₫$ Advanced simulation training can effectively enhance the faculty's competency in tooth preparation. Such training may be provided in the prosthodontic faculty development program to improve their tooth preparation competence before they begin preclinical teaching.

\section{Background}

Dentistry is a practical discipline with a high requirement for practitioner's hand dexterity and psychomotor ability. The preclinical hands-on curriculum in a simulated environment has become the main approach to aid the acquisition of manual skills in dental education before real-life clinical practice [1]. In this preclinical course, a high level of competence, including in expertise, knowledgeability, and skillfulness, has been identified to be the characteristic of effective teachers [2]. In the specialty of fixed prosthetic dentistry, crown preparation is one of the most essential and critical technical skills. Consequently, crown preparation training represents a very important topic both for undergraduate education in dentistry and continuing education in prosthodontics. It is obligatory for prosthodontic faculty to master standardized and precise tooth preparation technique since live operative demonstration by an instructor has always played a key role in simulation teaching. With the advance of multimedia technology, application of instructional videos depicting the detailed procedures of crown preparation has been popularized in modern preclinical curriculum, which to a certain extent obviates the need for personal demonstrations [3]. Nonetheless, the demand for high level tooth preparation skill in 
prosthodontic faculty remains indispensable because instructional videos are unable to fully substitute for the live demonstration under varied practice settings. Moreover, the interpersonal communication between faculty and students, including correcting the operative posture or evaluating the prepared work, requires that the faculty grasp this clinical competence well.

Although crown preparation is a basic operative skill in fixed prosthodontics, levels of tooth preparation skill vary inevitably among individual faculty in different dental schools or even in the same institution due to the diversity in personal talent, effort investment, educational background, and clinical experience. Even in experienced prosthodontic specialists, individual habits in tooth preparation are usually developed from clinical practice. Such habits may be favorable from a personal perspective and pragmatic for specific clinical cases but may be different from the standard protocols in the textbooks of fixed prosthodontics. Moreover, some new instructors who perform excellently in clinical practice may not adapt smoothly to operations on simulated mannequins with typodont tooth, considering the differences between real clinical situations and a simulated environment. Therefore, it is necessary to provide standardized tooth preparation training in a simulated environment for new preclinical instructors in order to prepare them better for teaching assignments and further improve their relative clinical competence [4]. Generally, faculty development for clinical instructors in dental education has been demonstrated to be effective in improving teaching performance $[5,6]$. In addition, the necessity for faculty development has been recognized by many dental schools $[7,8]$. In terms of the specific tooth preparation technique, however, the effect of certain standardized training for prosthodontic faculty has not been reported. The appropriate form and intensity of tooth preparation training should also be explored in order to ensure the effectiveness of training, while avoiding the potential waste of time and resources.

With the rapid development of digital technology, newly emerging digital tools have been introduced in dental clinical and preclinical settings. For example, the digital evaluation tools for grading tooth preparation competency in preclinical training by scanning the prepared tooth and comparing it to a stipulated gold standard have been applied in many dental institutions. It has been demonstrated that the use of digital evaluation systems in preclinical curriculum can assess students' performance more accurately and objectively, by precluding the variability and subjectivity inherent in the traditional visual inspection grading by faculty [9-11]. In addition, the digital evaluation system can directly show the discrepancies between the student's preparation and the standard preparation through visual sections in desired planes, which effectively improves the student's preclinical achievement by providing more explicit visual feedback than the traditional verbal instruction by faculty [12]. Owing to these advantages, the application of digital evaluation systems in preclinical training has been shown to effectively facilitate learning and enhance the tooth preparation compentency of dental students [13-16], and it seems to be a promising alternative to the traditional evaluation method in the preclinical course. Currently, in most dental schools in China, the traditional inspection grading by faculty remains the primary evaluation approach in preclinical education. Although digital evaluation systems have been introduced in several top dental schools in China, it mainly acts as a supplemental method for grading student's achievement in the preclinical course. 
Recently, a nationwide short-term faculty development workshop was launched by the Society of Prosthodontics, Chinese Stomatological Association, to advance the faculty's competence in standardized and precise crown preparation as well as to popularize the application of the digital grading approach for preclinical education. In this study, we investigated and analyzed the trainees' competence in tooth preparation before, during, and after this advanced training course based on the grades given by the digital evaluation system for anterior and posterior tooth preparation. Our results would have implications for the design of effective and feasible faculty development programs targeting the enhancement of tooth preparation skill in the future.

\section{Methods}

\section{Training process}

Fifty experienced prosthodontic faculties from 49 colleges of stomatology in China volunteered to participate in this training workshop, to further upgrade their crown preparation skills and learn the use of the digital evaluation system for grading the competency in tooth preparation. The general characteristics of the 50 trainees are shown in Table 1.

The training assignment consisted of preparing a maxillary right central incisor (11\#) for ceramo-metal crown as well as a mandibular left first molar (36\#) for metal crown in a simulated environment. Prior to this training course, the standard tooth model including 11\# and 36\# (A5SAN-2002, Nissin Dental Products Inc., Kyoto, Japan) was mailed to all trainees and the grading criterion of preparation was notified. All trainees were required to perform these crown preparations following their preferred habits with the standard jaw model (PRO2002-UL-SP-FEM-28, Nissin Dental Products Inc.) in their stimulated units. After arriving at the training site, they were asked to conduct these preparations again using the same on-site simulated clinic facilities (Senior type II Manikin, Nissin Dental Products Inc.), utilizing 30 minutes for each preparation. All the off-site and on-site preparations were assessed with a digital tooth preparation evaluation system (Fair Grader 2000, Nissin Dental Products Inc.), and the on-site scores were adopted as the pre-training achievements. Then, didactic instructions including principles, criteria, and rubric of standardized crown preparation were delivered by a senior fixed prosthodontic specialist, followed by a live demonstration of tooth preparation performed under a ZEISS OPMI pico dental microscope (Carl Zeiss Meditec AG, Oberkochen, Germany) that was broadcast to all trainees with the internal HD video system. A total of three practice rounds were carried out by all trainees at the on-site simulation clinic within the given time (30 minutes for each preparation). After each round of practice, the preparations were digitally evaluated and the results were timely conveyed to the corresponding operators, so that the deficiencies would be demonstrated and analyzed before the next round. After all the three rounds of practice, the summative examination was conducted with the same procedure as practiced previously. The final preparations were digitally graded and the scores were recorded as the post-training achievements. The entire training program protocol is shown in Fig. 1.

\section{Digital grading process}


All preparations were scanned by the Nissin Fair Grader 2000 system to create three-dimensional images constituted by point cloud data which accurately replicated the surface of tooth preparations. The system then superimposed the images of actual preparations on the ideal pre-defined criteria of preparation to analyze the differences and generate the final grades on a 0-100 scale as well as the deduction items such as the amount of reduction, margin line, and taper (total convergence angle). A PDF report with detailed scores was outputted, which also show deviations from the ideal standard preparation in horizontal, vertical, and oblique cross sections (Fig. 2).

\section{Statistics}

Data were analyzed using SPSS 20.0 (IBM Corporation, Armonk, New York, USA). All data are expressed as the mean \pm SEM and were tested for normality (Kolmogorov-Smirnov test) and equal variance. The scores of preparations acquired before and after training were compared by repeated measures one-way analysis of variance, followed by the Bonferroni post-hoc test. A P-value of $<0.05$ was considered statistically significant.

\section{Results}

\section{Total scores of 11\# and $36 \#$ preparations before and after training}

No difference in total scores was observed between 11\# prepared off-site and on-site before training. Compared with pre-training performance, 11 \# scores were significantly increased after the first round of practice following didactic lecture $(P<0.01)$, and remained at the same level after the second and third round of practice with feedback information from the digital evaluation system, as well as after the final test after training (Fig. 3).

No difference in total scores was detected between 36\# prepared off-site and on-site before training. Compared with pre-training performance, 36 \# scores were significantly increased after the first round of practice following didactic lecture $(P<0.05)$, were further increased after the second round of practice with feedback $(P<0.01)$, and remained at the same level after the third round of practice and final test (Fig. 3 ).

\section{Amount of reduction of $11 \#$ and $36 \#$ preparations before and after training}

No difference in marks deducted for amount of reduction was observed between 11\# prepared off-site and on-site before training. Compared with pre-training performance, points deducted for amount of reduction of 11\# preparations were significantly decreased after the first round of practice following didactic lecture $(P<0.01)$ and remained at the same level after the second and third round of practice with feedback, as well as after the final test (Fig. 4). According to the PDF reports, inadequate amount of reduction was frequently noted at the lingual fossa, the junction of the lingual fossa and the axial wall, and the line angle around the lingual fossa of $11 \#$ preparations. The excessive amount of reduction was often found at the incisal part of the labial axial surface of 11 \# preparations. 
No difference in marks deducted for amount of reduction was observed between 36\# prepared off-site and on-site before training. During training, points deducted for amount of reduction of $36 \#$ preparations tended to decline after the first round of practice following didactic lecture and continued to decline after the second round of practice with feedback, but the difference was not statistically significant. Compared with pre-training performance, marks deducted for amount of reduction of 36 \# preparations after the second round of practice and the final test after training were significantly decreased $(P<0.01)$ (Fig. 4). According to the PDF reports, inadequate amount of reduction was usually noted at the center of the occlusal surface and the functional bevel of $36 \#$ preparations. Excessive amount of reduction was generally observed at the distal axial surface and buccal cusp of $36 \#$ preparations.

\section{Margin line of $11 \#$ and $36 \#$ preparations before and after training}

No difference in marks deducted for margin line was observed between 11\# prepared off-site and on-site before training. Compared with pre-training performance, points deducted for margin line of 11\# preparations significantly decreased after the first round of practice following lecture $(P<0.01)$; however, the decline of magnitude of deduction after the second and third round of practice with feedback were not statistically significant. Marks deducted for margin line of 11\# preparations of the final test were significantly decreased than that prepared pre-training $(P<0.05)$ (Fig. 5). The margin line of the actual 11\# preparations was easily shallower than the standard preparations.

No difference of marks deducted for margin line was observed between 36\# prepared off-site and on-site before training. During the training process, points deducted for margin line of 36 \# preparations declined after the first round of practice following didactic lecture and continued declining after the second round of practice with feedback; however, the differences were not statistically significant. Compared with pretraining performance, marks deducted for margin line of 36 \# preparations after the second round of practice $(P<0.05)$ and the final test $(P<0.01)$ were significantly decreased $($ Fig. 5$)$.

\section{Taper of 11\# and 36\# preparations before and after training}

No differences in marks deducted for taper were observed between 11\# prepared off-site and on-site before training, as well as among that prepared after three rounds of practice and the final test (Fig. 6).

Marks deducted for taper of $36 \#$ prepared on-site before training was significantly increased compared with that prepared off-site. During training, points deducted for taper of $36 \#$ preparations tended to decline after the first round of practice following didactic lecture and further declined after the second and third round of practice with feedback, but the differences were not statistically significant. Marks deducted for taper of $36 \#$ preparations of the third round of practice and the final test were significantly decreased compared with that of the pre-training performance $(P<0.01)$ (Fig. 6). The excessive reduction of the distal surface was the most common cause of over scale taper of the $36 \#$ preparations according to the PDF output. Generally, marks deducted for taper of 11\# preparations were obviously smaller than that of $36 \#$ preparations. 


\section{Discussion}

With the aid of digital evaluation technology, tooth preparation completed by every trainee can be assessed more objectively with the uniform grading criterion and accurately compared with the traditional method of visual grading $[9,10,11]$. These advantages of the digital evaluation system made it feasible to investigate the effect of repeated training practice on the trainees' competency in tooth preparation in a reliable and effective manner.

To reduce the potential effect that may lower the pre-training achievements due to lack of familiarity with the simulated tooth preparation process, every trainee was asked to conduct the tooth preparation task twice before training. At the first time, all trainees used their own facilities off the training site to perform the task in order to make themselves familiar with the procedure and grading criteria of simulated tooth preparation. At the second time, right before the training started, they were asked to use the uniform onsite facilities to repeat the task, and the corresponding scores were adopted as the trainees' pre-training competency. Scores of the off-site and on-site performances were compared and no difference was detected regarding the total scores, marks deducted for amount of reduction and margin line of $11 \#$ and $36 \#$ preparations, as well as deductions in the taper of 11\# preparations. These results suggested that the lack of familiarity of some dental faculty with simulation training does not affect the total tooth preparation performances and most of the parameters of tooth preparation. The results also indicated that the trainees' performances were relatively stable considering they are from experienced prosthodontic faculty, and repeated practices per se without further training are unable to improve their tooth preparation skill. Interestingly, marks deducted for taper of 36\# preparations completed on-site were significantly increased compared with those prepared off-site. The result may be explained by the possibility that some trainees may prepare $36 \#$ directly in their hands instead of in the set-up in the stimulated model without supervision. However, it is easier to control the taper of posterior tooth preparation in the former situation.

Through the whole training program, total scores of $11 \#$ and 36 \# preparations of the final test were significantly increased compared with pre-training achievements. Marks deducted for amount of reduction and margin line of the prepared $11 \#$ and $36 \#$, as well as deductions of the taper of the prepared $36 \#$, were significantly decreased compared with before training. These results indicated this training program can effectively enhance the trainees' competency in tooth preparation. There was no significant difference in the deductions of the taper of prepared 11\# between pre-training and post-training performance; this may be because the trainees have sufficient awareness about how to control the taper of the anterior tooth preparation based on their previous experience. The taper of anterior tooth preparation is easier to manage than that of posterior tooth preparation considering the former can be viewed and judged in the front directly but the latter cannot. Based on the present data, we can further analyze the different training effects for anterior and posterior tooth preparation. For anterior tooth preparation, the total scores and marks deducted for amount of reduction and margin line after the first round of practice following the didactic lecture showed the maximum improvement. No further improvement was observed after the second and third round of practice with feedback evaluation. For 
posterior tooth preparation, increased total scores were observed after the first round of practice following the didactic lecture and the total scores were further increased after the second round of practice with feedback. The most obvious improvement in amount of reduction and margin line of posterior tooth preparation was found after the second round of practice, and significant decrease in the marks deducted for taper was observed after the third round of practice. These results are in line with the common knowledge that the more difficult a procedure is, the more is the practice required. Crown preparation of an anterior tooth is easier than that of a posterior tooth considering the convenience in access for operation as a result of the anterior position of the tooth. Therefore, in order to further improve the performance of skilled faculty in tooth preparation, one round of practice following a detailed lecture will be sufficient for anterior tooth preparation, while one or two more rounds of practice will be needed for posterior tooth preparation. Moreover, the present results also suggested that it may be unnecessary to add more practices for skilled faculty as no further improvement was exhibited.

The training workshop comprised a didactic lecture elaborating the standard principles of crown preparation and recommendations to avoid potential deficiencies and a live demonstration of tooth preparation under dental microscope with real-time synchronized broadcast delivered by a senior prosthodontic professional, as well as the following three rounds of practice with feedback by a digital evaluation system. As skilled prosthodontic faculty, the trainees may not gain substantial new knowledge from the didactic lecture and live demonstration. Instead, these training patterns may mainly refresh the trainee's existing memory regarding the tooth preparation technique and provide a reminder about some tips to minimize common errors. However, this kind of training modality seems to be very effective in improving the trainees' performance for simulated anterior as well as posterior tooth preparation based on the results. This lecture and live demonstration can be replaced by a recorded video with similar content to further reduce the training cost for future course design. The repeated hands-on practices with feedback also seem to play significant roles in further improving the trainees' skill for tooth preparation, especially for the posterior teeth. Feedback has been considered a fundamental means for effective clinical teaching and plays a critical role in improving learners' performance $[17,18]$. In this training course, immediate feedback was provided by a digital evaluation system following each practice, which may reduce potential subjective errors and enhance the efficacy of feedback compared with selfevaluation by trainees. However, it should be emphasized that we cannot prove whether this digital feedback is indispensable for the effectiveness of this training course. Unlike undergraduate students who are incapable of properly evaluating the prepared tooth on their own $[19,20]$, the trainees are from skilled prosthodontic faculty who should have reliable self-assessment ability. Considering inherent limitations of the one group "pretest-posttest" design of this investigation, further studies with a rigorously controlled trial design should be conducted to confirm the role of a specific training intervention in order to develop a more economic and effective training modality in the future.

\section{Conclusion}

Advanced simulation training can effectively improve the quality of tooth preparation completed by prosthodontic faculty, which can be provided in a prosthodontic faculty development program to improve 
their competency in tooth preparation, especially before being assigned the preclinical teaching task. Further, more practice is needed to enhance the skill for posterior tooth preparation compared with anterior tooth, and an individualized training design should be developed considering the different tooth positions.

\section{Declarations}

\section{Ethics approval and consent to participate}

Not applicable. This training workshop was officially launched by the Society of Prosthodontics, Chinese Stomatological Association. All trainees were volunteered to participate in this training program to further upgrade their crown preparation skills and learn the use of the digital evaluation system. Data collected for this report were from all the prepared model teeth which were sponsored by Nissin Dental Products Co., Ltd. The authors have been authorized to using these data for analysis and publication.

\section{Consent for publication}

Not applicable.

\section{Availability of data and materials}

The datasets used and/or analysed during the current study are available from the corresponding author on reasonable request.

\section{Competing interests}

The authors declare that they have no competing interests.

\section{Funding}

This work was supported by the Program for Educational Reform of Peking University School and Hospital of Stomatology (2017-ZD-07).

\section{Authors' contributions:}

Xiaoxiang Xu contributed to analysis and interpretation of data and drafting the manuscript. Qiufei Xie contributed to the design of the study and revising the manuscript critically. Yongsheng Zhou contributed to the conception and design of the study and revising the manuscript critically. Lei Wu contributed to the acquisition of data and revising the manuscript critically. Ye Cao contributed to the design of the study, the acquisition, analysis and interpretation of data and revising the manuscript critically. All authors read and approved the final manuscript.

\section{Acknowledgements}


We thank the support from the Society of Prosthodontics, Chinese Stomatological Association and Prof. Hongchen Liu for this training program. We thank Carl Zeiss (Shanghai) Co., Ltd. And Nissin Dental Products Co., Ltd. for providing the on-site facilities and technical support.

\section{References}

1. Perry S, Bridges SM, Burrow MF: A review of the use of simulation in dental education. Simulation in healthcare : journal of the Society for Simulation in Healthcare 2015, 10(1):31-37.

2. McAndrew M, Mucciolo TW, Jahangiri L: Characteristics of Effective Simulation (Preclinical) Teachers as Identified by Dental Students: A Qualitative Study. J Dent Educ 2016, 80(11):1282-1293.

3. Aragon CE, Zibrowski EM: Does exposure to a procedural video enhance preclinical dental student performance in fixed prosthodontics? J Dent Educ 2008, 72(1):67-71.

4. Hunt CW, Curtis AM, Gore T: Using Simulation to Promote Professional Development of Clinical Instructors. The Journal of nursing education 2015, 54(8):468-471.

5. Hendricson WD, Anderson E, Andrieu SC, Chadwick DG, Cole JR, George MC, Glickman GN, Glover JF, Goldberg JS, Haden NK et al: Does faculty development enhance teaching effectiveness? J Dent Educ 2007, 71(12):1513-1533.

6. Moystad A, Lycke KH, Barkvoll TA, Lauvas P: Faculty development for clinical teachers in dental education. Eur J Dent Educ 2015, 19(3):149-155.

7. O'Neill PN, Taylor CD: Responding to the need for faculty development: a survey of U.S. and Canadian dental schools. J Dent Educ 2001, 65(8):768-776.

8. Behar-Horenstein LS, Garvan CW, Catalanotto FA, Su Y, Feng X: Assessing Faculty Development Needs among Florida's Allied Dental Faculty. Journal of dental hygiene: JDH 2016, 90(1):52-59.

9. Cardoso JA, Barbosa C, Fernandes S, Silva CL, Pinho A: Reducing subjectivity in the evaluation of preclinical dental preparations for fixed prosthodontics using the Kavo PrepAssistant. Eur J Dent Educ 2006, 10(3):149-156.

10. Kateeb ET, Kamal MS, Kadamani AM, Abu Hantash RO, Abu Arqoub MM: Utilising an innovative digital software to grade pre-clinical crown preparation exercise. Eur J Dent Educ 2017, 21(4):220-227.

11. Mays KA, Crisp HA, Vos P: Utilizing CAD/CAM to Measure Total Occlusal Convergence of Preclinical Dental Students' Crown Preparations. J Dent Educ 2016, 80(1):100-107.

12. Hamil LM, Mennito AS, Renne WG, Vuthiganon J: Dental students' opinions of preparation assessment with E4D compare software versus traditional methods. J Dent Educ 2014, 78(10):14241431. 
13. Liu L, Li J, Yuan S, Wang T, Chu F, Lu X, Hu J, Wang C, Yan B, Wang L: Evaluating the effectiveness of a preclinical practice of tooth preparation using digital training system: A randomised controlled trial. Eur J Dent Educ 2018, 22(4):e679-e686.

14. Morrow JA, Pulido MT, Smith PB, McDaniel TF, Willcox AB: Effective use of e-grading in the dental simulation clinic. J Dent Educ 2014, 78(6):829-837.

15. Nagy ZA, Simon B, Toth Z, Vag J: Evaluating the efficiency of the Dental Teacher system as a digital preclinical teaching tool. Eur J Dent Educ 2018, 22(3):e619-e623.

16. Tiu J, Cheng EX, Hung TC, Yu CC, Lin T, Schwass D, Al-Amleh B: Effectiveness of Crown Preparation Assessment Software As an Educational Tool in Simulation Clinic: A Pilot Study. Journal of Dental Education 2016, 80(8):1004-1011.

17. Cantillon P, Sargeant J: Giving feedback in clinical settings. BMJ 2008, 337:a1961.

18. Ende J: Feedback in clinical medical education. JAMA 1983, 250(6):777-781.

19. Cho GC, Chee WW, Tan DT: Dental students' ability to evaluate themselves in fixed prosthodontics. J Dent Educ 2010, 74(11):1237-1242.

20. Habib SR, Sherfudhin H: Students' self-assessment: a learning tool and its comparison with the faculty assessments. J Contemp Dent Pract 2015, 16(1):48-53.

\section{Table 1}

Table 1 General characteristics of the 50 trainees

\begin{tabular}{ccccc}
\hline Age $(\mathrm{y})$ & Sex & \multicolumn{3}{c}{ Type of institution } \\
\hline Female $(\mathrm{n})$ & Male $(\mathrm{n})$ & Undergraduate college $(\mathrm{n})$ & Technical college $(\mathrm{n})$ \\
$39.22 \pm 7.02$ & 40 & 10 & 32 & 18 \\
\hline
\end{tabular}

\section{Figures}




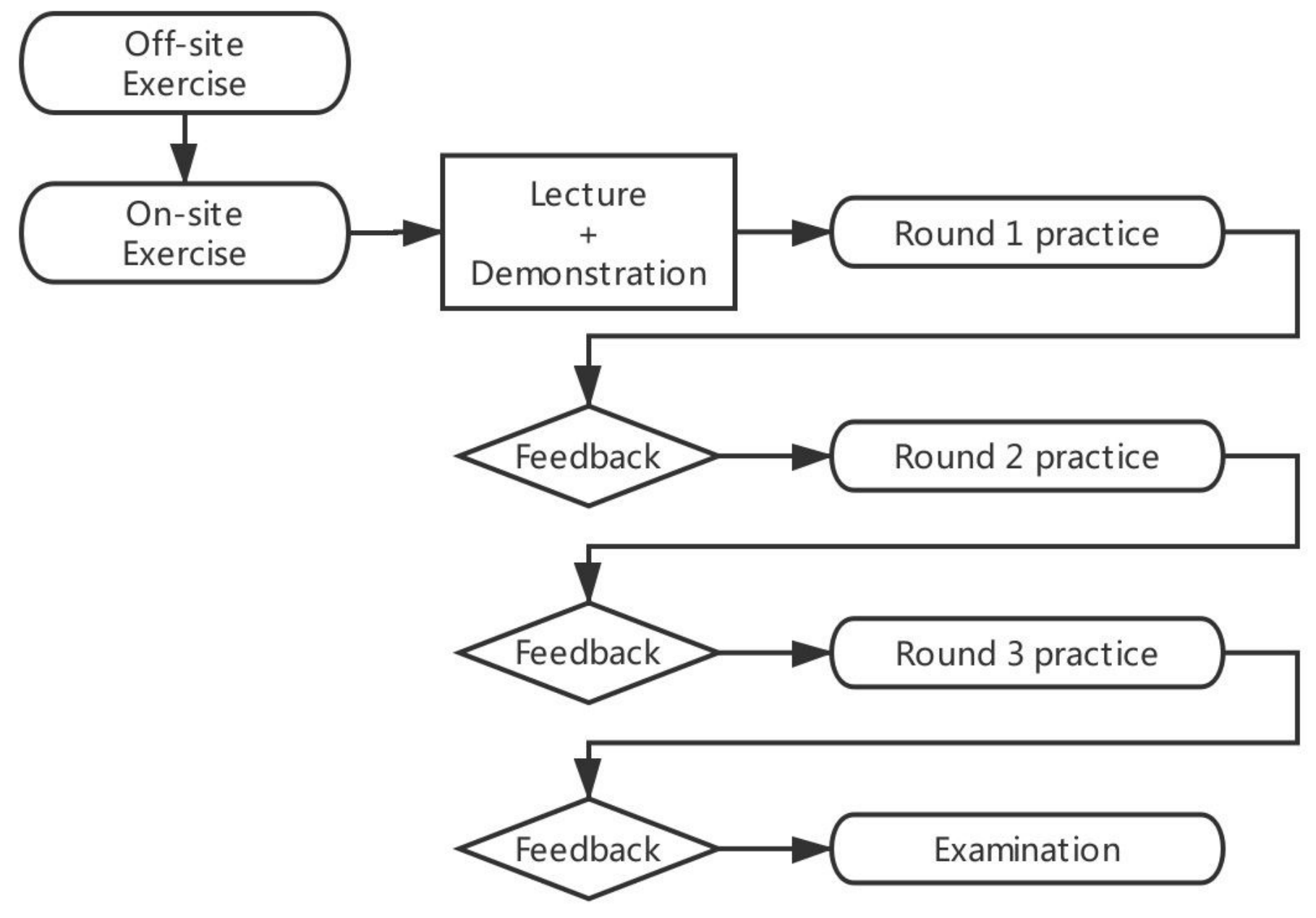

Figure 1

Flow chart of the advanced stimulated training course 
切削过多 切削不足

Excessive reducton Insufficient cutting

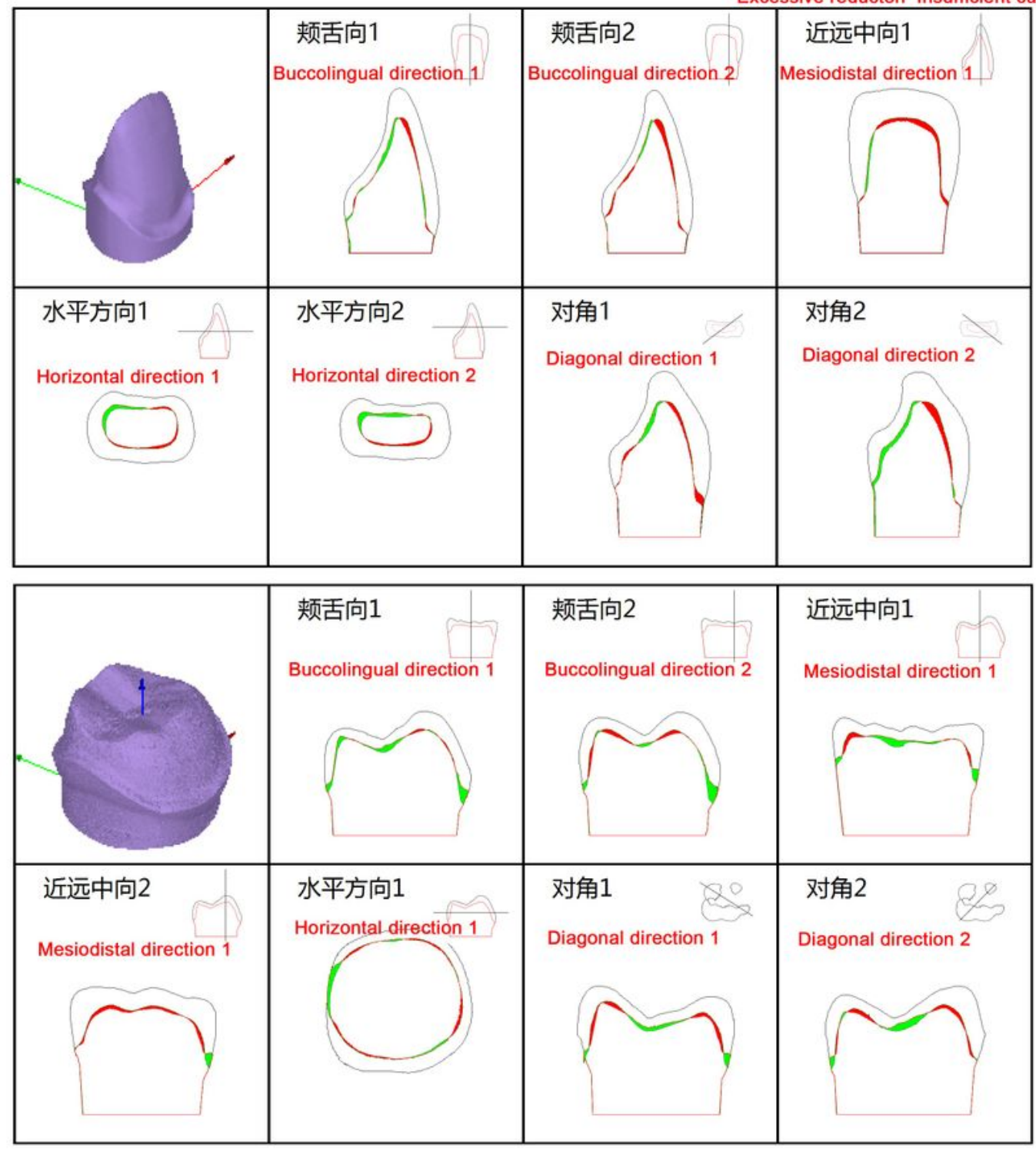

\section{Figure 2}

Examples of PDF reports produced by the Nissin Fair Grader 2000 system (Nissin Dental Products Inc., Kyoto, Japan) showing deviations of the anterior or posterior preparations from the ideal standard preparation in horizontal, vertical, and oblique cross sections 

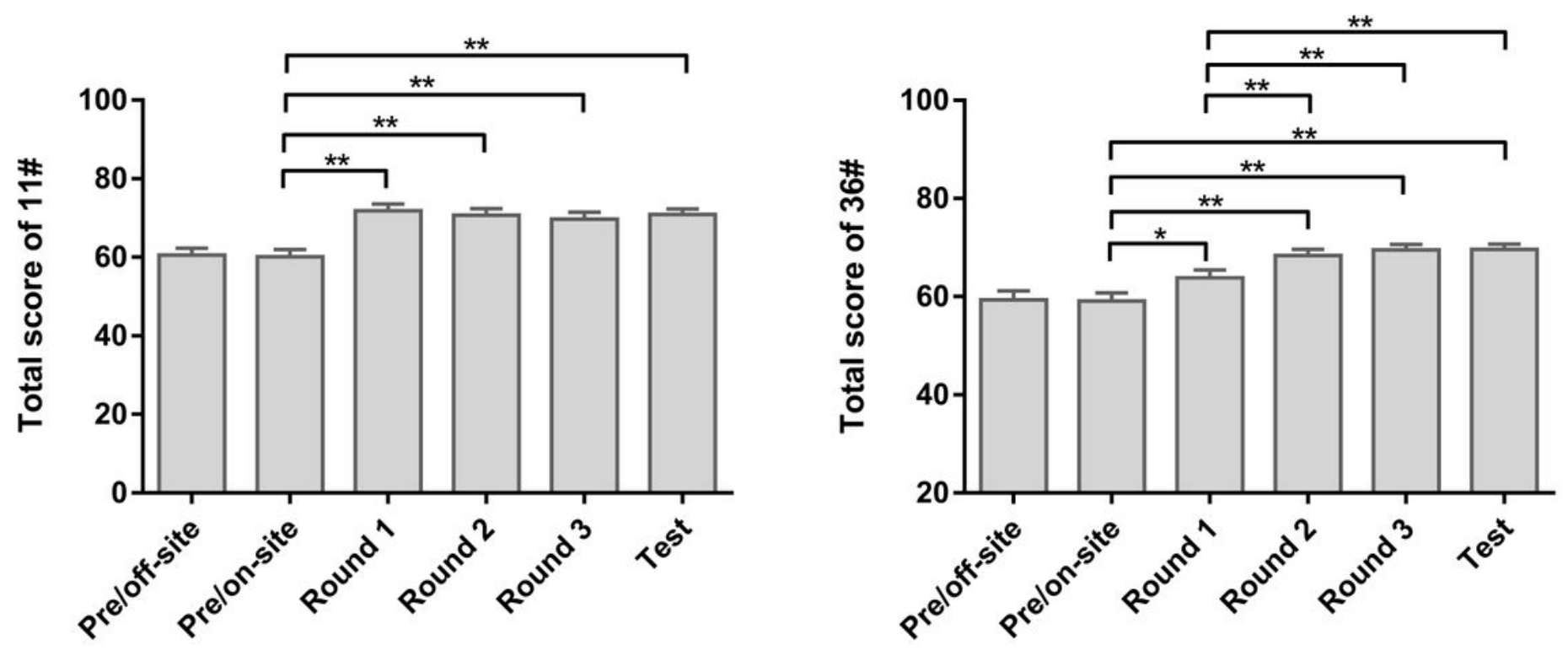

Figure 3

Total scores of $11 \#$ and $36 \#$ preparations performed off-site and on-site before the training course $\mathbb{}$ after three rounds of practice, and after the final test. *, $\mathrm{P}<0.05$; $\star \star, ~ P<0.01$.
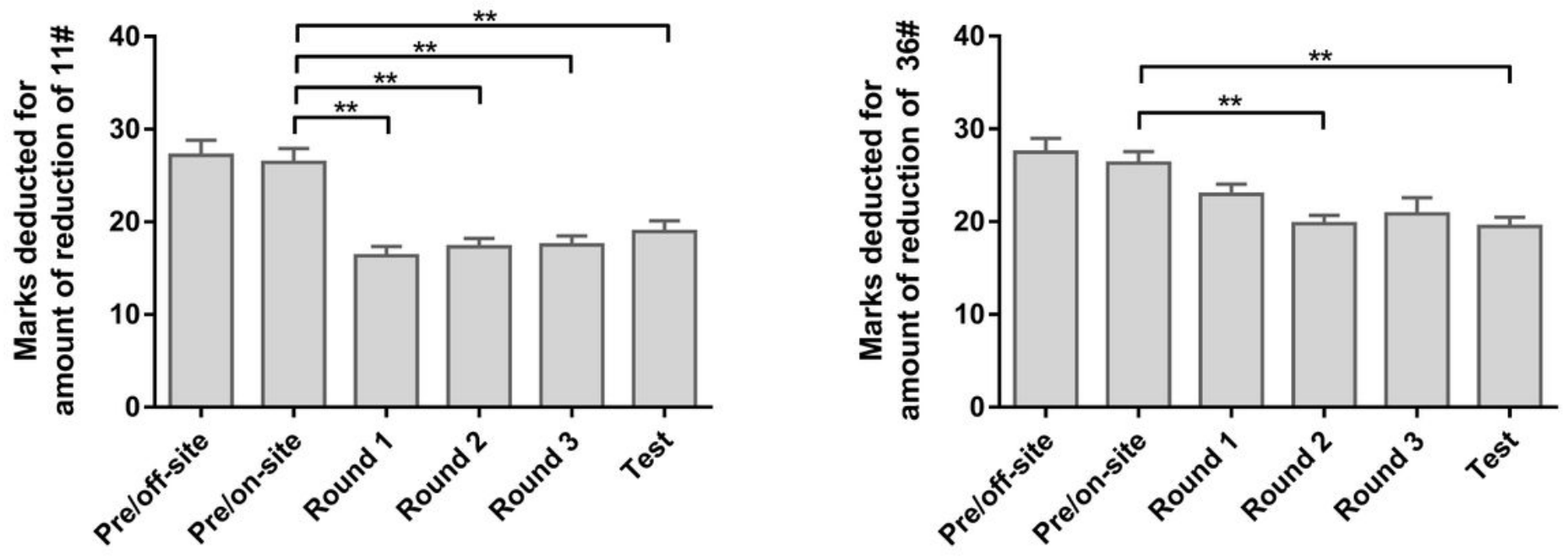

Figure 4

Marks deducted for amount of reduction of 11\# and $36 \#$ preparations performed off-site and on-site before the training course冈after three rounds of practices, and after the final test. **, $P<0.01$. 

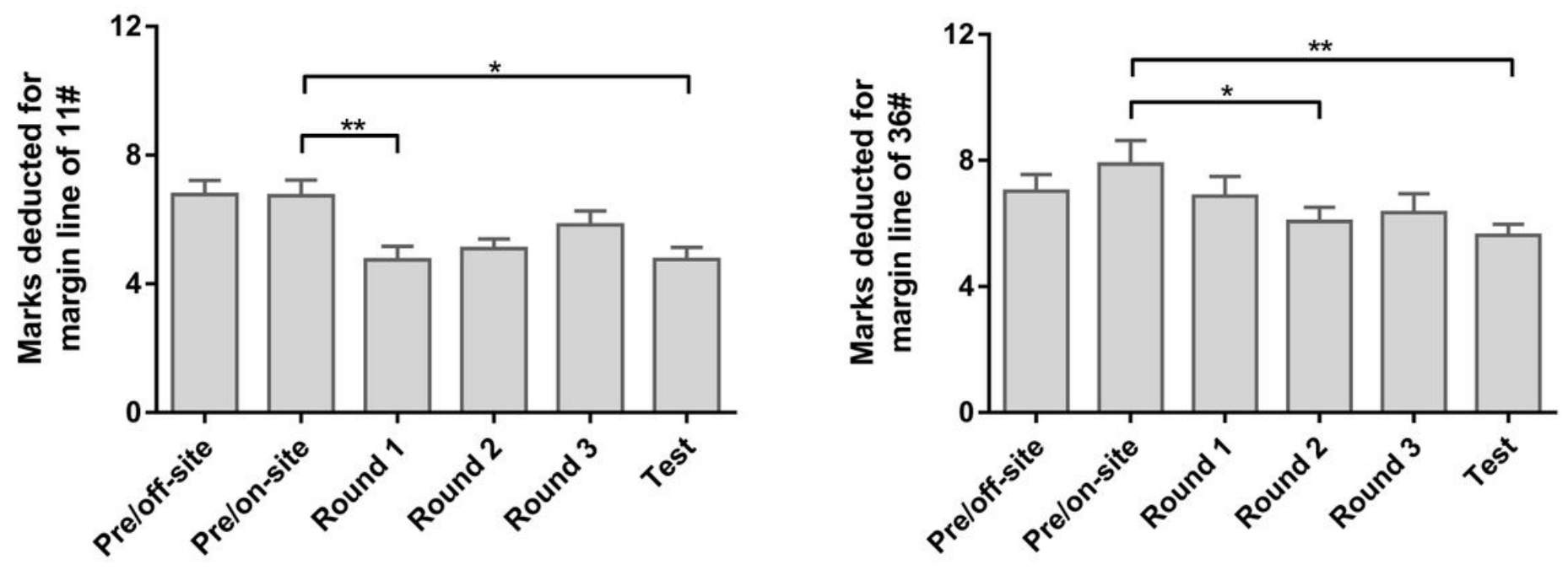

Figure 5

Marks deducted for margin line of $11 \#$ and $36 \#$ preparations performed off-site and on-site before training course, after three rounds of practice, and after the final test. ${ }^{*}, P<0.05 ; \star \star, P<0.01$.
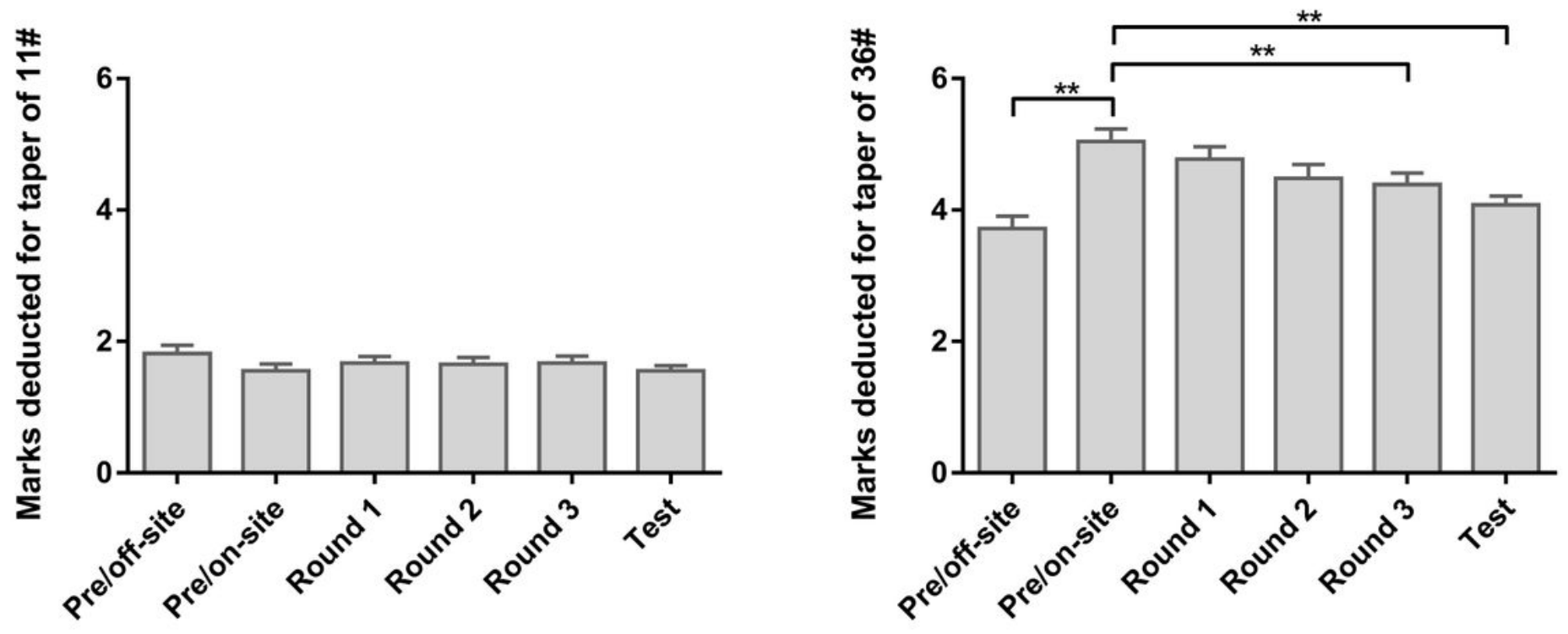

Figure 6

Marks deducted for taper of $11 \#$ and $36 \#$ preparations performed off-site and on-site before the training course, after three rounds of practice, and after the final test. **, $P<0.01$. 